\title{
EAHP survey and European Statements of Hospital Pharmacy - can we achieve a perfect match?
}

\author{
Petr Horák, ${ }^{1,2}$ Joan Peppard, ${ }^{1,3}$ Juraj Sýkora, ${ }^{1,4}$ Tajda Miharija Gala ${ }^{1,5}$
}

${ }^{1}$ European Association of Hospital Pharmacists, Brussels, Belgium

${ }^{2}$ University Hospital Motol, Hospital Pharmacy, Prague, Czech Republic

${ }^{3}$ Midland Regional Hospital

Tullamore, Tullamore, Ireland

${ }^{4}$ Pharmacy Department SZU,

National Cancer Institute,

Bratislava, Slovakia

${ }^{5}$ Pharmacy Department,

University Medical Centre

Ljubljana, Ljubljana, Slovenia

Correspondence to

Dr Petr Horák,

European Association

of Hospital Pharmacists,

Rue Abbé Cuypers,

3 B-1040 Brussels, Belgium;

horak@hospitalpharmacy.cz

Received 7 August 2014 Accepted 8 August 2014

\section{(1) crossanat}

To cite: Horák P, Peppard J, Sýkora J, et al. Eur J Hosp Pharm 2014;21:291-293.

\section{ABSTRACT}

The European Summit on Hospital Pharmacy 'examined and determined' what the role of hospital pharmacy practice should be in today's Europe, and the Statements were agreed by hospital pharmacists and external stakeholders. However, their implementation is challenging. The 2014 European Association of Hospital Pharmacists (EAHP) General Assembly dedicated considerable time to determining the most difficult and important issues. For 20 years the EAHP Survey has been the main tool to identify the state-of-art of the profession throughout Europe, but it is now time to re-think survey procedures so that it will provide EAHP and its members with quicker and more relevant feedback and information. Therefore, a new model with a 3-year cycle has been developed and approved by the General Assembly. A set of questions that can be properly evaluated should be devised and a

benchmarking tool built. Many other issues also need to be resolved in the next few months.

\section{INTRODUCTION}

The 2014 European Summit on Hospital Pharmacy has elaborated a new and very broad description of what hospital pharmacy is and especially what the key roles of today's European hospital pharmacist are or should be. With its focus on Europe and using an innovative approach to bring patients, physicians, other healthcare professionals and, of course, hospital pharmacists together to develop and approve Summit Statements, the Summit is a real milestone in the development of the profession. The Europe-wide implementation of the Summit Statements will promote patient safety and support the optimisation of clinical outcomes. However, there are many obstacles and challenges to implementation.

\section{CHALLENGES FOR THE IMPLEMENTATION OF SUMMIT STATEMENTS}

Initial work on the European Statements was based on the global International Pharmaceutical Federation (FIP) Statements. It became clear that rewording and adjusting the Statements to the European situation would make them more pertinent to the daily practice. On the other hand, as Europe itself has many different healthcare systems and levels of economic development, the roles of hospital pharmacists also differ.

Therefore, during the first post-Summit EAHP General Assembly, workshops provided EAHP Board Members and delegates with feedback on implementation and metrics. Delegates were split into six groups representing each of the six major Statement sections. The international composition of the groups was designed to achieve the widest possible range of views. The delegates were asked to discuss all the Statements in their section and rate them according to implementation challenges and priorities, bearing in mind EAHP educational activities including the forthcoming work on the Common Training Framework for hospital pharmacy specialisation. ${ }^{1}$

Based on the presentations given by the representatives of each group, the common impression of the delegates was that the biggest challenges were the differences in levels of practice and healthcare systems across Europe.

Delegates discussing Section 1 (Introductory Statements and Governance) agreed with the importance of focussing on outcome measurement in every hospital pharmacy and collecting the necessary data, as well as developing and maintaining proper staffing plans and also providing proper training of hospital pharmacists in information and communication technologies.

Delegates discussing Section 2 (Selection, Procurement and Distribution) declared that Statements 2.1 (hospital pharmacist involvement in procurement) and 2.4 (formulary system) had generally already been implemented in EAHP member countries, while implementation of the other Statements could be improved. The group recommended the use of the new EAHP Survey and a proper benchmarking tool (see below) in future.

Delegates discussing Section 3 (Production and Compounding) found risk assessment (Statement 3.3) procedures undertaken before pharmacy preparation to be both highly challenging and of high priority, and emphasised that international cooperation and knowledge exchange on this issue is particularly important. They also mentioned the very different ways of handling hazardous substances (Statement 3.5) throughout Europe. Similarly to the group considering Section 1, the delegates discussed staffing matters, especially as related to Statement 3.6 (on-site reconstitution).

Delegates discussing Section 4 (Clinical Pharmacy Services) identified Statement 4.2 (validation of prescriptions) as the biggest challenge, again linked with high staffing demands. In the context of the Common Training Framework, the group found Statement 4.3 (access to patients' health record and documentation of all interventions) to be the most important.

Delegates discussing Section 5 (Patient Safety and Quality Assurance) considered Statement 5.2 and 5.4 on medication error detection reporting to be ones of the hardest to implement. The Group reflected that a system of pharmacovigilance not only needs to be implemented, but also practiced. 
Similarly, the traceability of all medicines dispensed by a pharmacy (Statement 5.11) seemed to be very difficult to achieve. The group said that Statement 5.1 (the seven rights of the patient) was the most important Statement.

Delegates discussing Section 6 (Education and Research) identified Statements 6.1 and 6.3 as major implementation challenges. While Statement 6.1 (undergraduate university curricula) is not deemed quite as important now (and falls outside hospital pharmacists' authority and responsibility), Statement 6.3 (Common Training Framework) covers a difficult and important topic. ${ }^{2} 3$

\section{WHAT THE STATEMENTS MEAN FOR}

\section{FUTURE EAHP SURVEYS}

Over the past two decades, the EAHP Survey has been the traditional tool for gathering data about the profession. With its wide scope and 5-year cycle, it has been the definitive source of information for many EAHP policies.

The Summit discussed the topics and agreed on the set of approved Statements defining the hospital pharmacists' profession. The EAHP and its members need to have a general idea of the current and future situation of the profession in member countries so that we know where we are now and can measure the future progress. Furthermore, technical tools for data collection have been continuously developing, offering many possibilities for fast and efficient data collection.

The EAHP Board established a Survey Working Group consisting of four Board Members with support from EAHP staff, to develop a revised survey model, better reflecting today's opportunities and the implementation of Summit Statements, with a focus on high response rates.

Based on the feedback from EAHP delegates during previous General Assemblies, the working group defined the essential requirements of the new survey:

- A much shorter length

- Conducted on a regular basis, annually or biannually

- Covering only important topics

- Gathering of basic statistical data should be done centrally, not directly from hospital pharmacies

- Clear objectives as to why the data are needed

- Survey results should be published quickly.

After much discussion and investigation, the EAHP Board and subsequently the General Assembly adopted the new model based on EAHP Summit Statements.

The survey will have two sections:

- Members' questionnaire: the aim of this section is to collect and maintain basic statistical data about member countries and organisations that are not available from other freely accessible resources. This survey is also required for the internal running of the EAHP. It is to be conducted annually, with only one response expected per country. This questionnaire will replace the traditional 'Country reports' filled in by national delegations before the annual General Assembly with a more structured form. For the proposed timeline see figure 1.

- An EAHP Practice Survey will also be carried out annually. To comply with the recommended 3-year cycle, each year's survey will cover only two of the six sections of the Summit Statements. For the proposed timeline see figure 2.

\section{FURTHER STEPS IN DEVELOPING THE NEW EAHP SURVEY}

With clear support from the General Assembly, the EAHP Survey Working Group is continuing to work on the new format. The most important and challenging step that will determine the future quality of survey outcomes is to identify

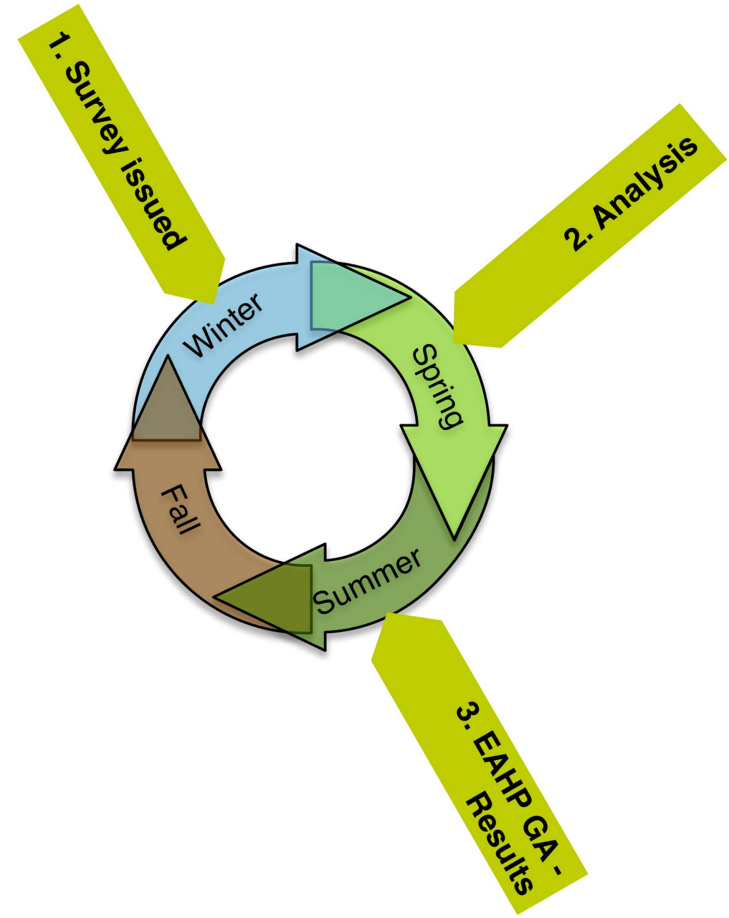

Figure 1 Timeline of members questionnaire. GA, General Assembly.

measurable indicators for the Statements thus allowing high quality statistical evaluation. Establishing the database and appointing the most suitable provider for the technical part of the survey is ahead of us. The group will probably produce a draft set of test questions and will seek feedback from members as to whether they consider the questions applicable, easy to understand and answer, etc. Progress in these areas is expected in the next few months.

\section{BENCHMARKING TOOLS}

One possible way to improve the usefulness of the next survey for EAHP, for its member associations and even for an

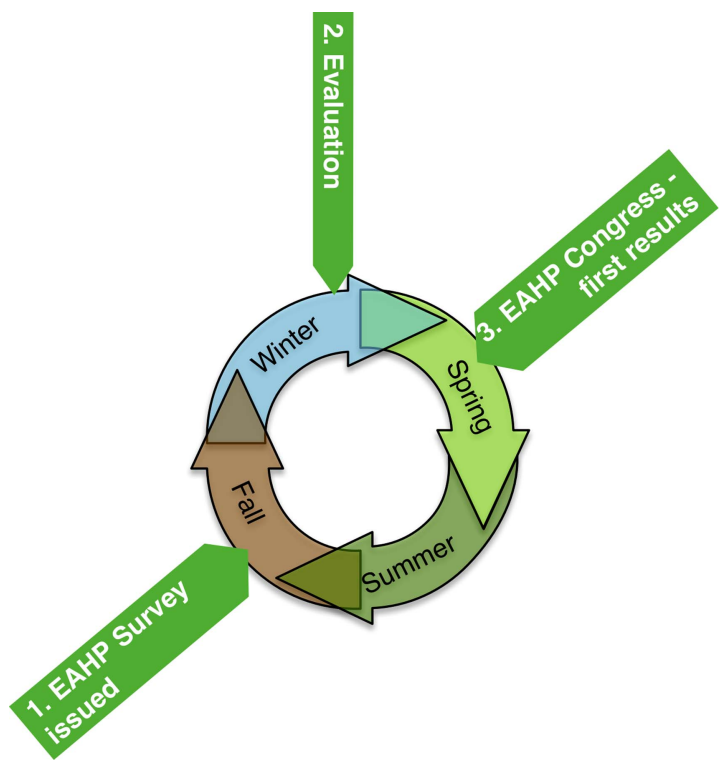

Figure 2 Timeline of the European Association of Hospital Pharmacists (EAHP) Survey. 
individual hospital pharmacy and hospital pharmacists, is to establish a benchmarking tool, allowing each hospital pharmacy to see and follow progress in Statement implementation. One source of inspiration may be the ASHP's Pharmacy Practice Model Initiative ${ }^{4}$ with its self-assessment tools.

The Survey Working Group believe that the use of benchmarking tools would improve the EAHP Survey response rate and also help its members when negotiating with national authorities.

However the development of benchmarking tools is costly. The advantages and disadvantages of having and maintaining a benchmarking system at the European level were widely discussed during the 2014 EAHP General Assembly. Apart from the cost, differences in healthcare systems in Europe was the most important reason why developing a European benchmarking system might be of questionable value. However, many delegates considered benchmarking tools as ideal for identifying weaknesses in their systems and practice, as well as providing encouragement for the continuing implementation of the European Statements of Hospital Pharmacy. As the new model of the EAHP Survey is now in the initial stages, the General Assembly delegates decided that the EAHP Board and staff should also investigate the possibilities and potential costs associated with a benchmarking tool for the next General Assembly in Porto in June 2015.

\section{CONCLUSION}

Implementation of the European Statements of Hospital Pharmacy in order to achieve the best outcomes for European hospital patients remains a challenge. EAHP General Assembly delegates discussed the Statements in depth during the dedicated workshops, identifying priorities and difficulties with implementation, as well as EAHP educational activities that could help with implementation. Generally, the biggest challenges in implementing the Statements are the varying levels of practice, different healthcare systems, and problems with staffing, but it is essential to measure advances in implementation for the benefit of hospital patients across Europe.

Based on previous feedback and the Summit, EAHP has decided to change its data collection tool, the EAHP Survey, by designing a shorter annual survey, optimising data collection while minimising workload for survey respondents.

Additional benchmarking tools to identify levels of implementation in the different hospitals are now under investigation.

Contributors The authors are members of the EAHP Board's Survey Working Group and participated in the review and development of the new approach to the EAHP Survey. They also served as facilitators during the dedicated General Assembly Workshops.

Competing interests None.

Provenance and peer review Commissioned; internally peer reviewed.

\section{REFERENCES}

1 European Parliament improves professional qualification rules [Online]. Published 29 Oct 2013. [Cit. 7. 8. 2014]. http://www.eahp.eu/press-room/european-parliamentimproves-professional-qualification-rules

2 EAHP GA Minutes drafted by Jennie de Greef. Email communication, July 2014.

3 European Statements on Hospital Pharmacy. [online]. [Cit. 6. 8. 2014]. http://www. eahp.eu/sites/default/files/files/European\%20Statements\%20f\%20Hospital\% 20Pharmacy.pdf

4 ASHP Pharmacy Practice Model Initiative. [online]. [Cit. 6. 8. 2014]. http://www. ashpmedia.org/ppmi/ 